\title{
Trabalho colaborativo entre discentes: Uma estratégia de ensino na aprendizagem de Matemática na Educação de Jovens e Adultos
}

\author{
Trabajo colaborativo entre estudiantes: Una estrategia de enseñanza en el \\ aprendizaje de Matemática en la Educación de Jóvenes y Adultos
}

\author{
Collaborative work among students: A teaching strategy in learning \\ mathematics in youth and adult education
}

Katiúscia Texeira Dias Ortiz ${ }^{1}$

\begin{abstract}
Resumo
Este artigo versa sobre os limites e as possibilidades do trabalho colaborativo entre discentes como uma estratégia na aprendizagem de Matemática, na inclusão do aluno com deficiência intelectual, na Educação de Jovens e Adultos (EJA) e tem por base a Teoria Histórico-Cultural da Atividade (CHAT). Stetsenko (2016) destaca que o educando deve passar por experiências de ensino e aprendizagem, que disponibilizem as ferramentas necessárias para resolver problemas em colaboração com os demais, permitindo que o aluno tenha voz ativa dentro do contexto escolar, potencializando o conhecimento a ser constituído de forma coletiva. Neste contexto, cabe ao professor mediar e observar os processos de ensino e aprendizagem dos alunos da EJA, possibilitando estratégias pedagógicas que estimulem as zonas de desenvolvimento reais e potenciais dos discentes. Almeja-se que numa educação inclusiva haja rupturas de paradigmas no ambiente escolar. Desta forma novas práticas pedagógicas devem ser construídas, possibilitando o desenvolvimento das capacidades e potencialidades dos alunos, buscando o seu desenvolvimento integral e proporcionando o compartilhamento de informações e conhecimentos por todos os envolvidos nos processos de ensino e aprendizagem. Vislumbrando contemplar esse cenário, também se faz uma análise reflexiva sobre o ordenamento legal que referencia a Educação Especial numa perspectiva inclusiva na EJA.
\end{abstract}

Palavras-chave: Trabalho colaborativo- Inclusão- EJA- Matemática

\section{Resumen}

Este artículo versa sobre los límites y las posibilidades del trabajo colaborativo entre discentes como una estrategia en el aprendizaje de Matemática, en la inclusión del alumno con discapacidad intelectual, en la Educación de Jóvenes y Adultos (EJA) y tiene como base la Teoría Histórico-Cultural de la Actividad (CHAT). Stetsenko (2016) destaca que el educando debe pasar por experiencias de enseñanza y aprendizaje, que pongan a disposición las herramientas necesarias para resolver problemas en colaboración con los demás, permitiendo que el alumno tenga voz activa dentro del contexto escolar, potenciando el conocimiento a ser constituido forma colectiva. En este contexto, corresponde al profesor mediar y observar los procesos de enseñanza y aprendizaje de los alumnos de la EJA, posibilitando estrategias pedagógicas que estimulen las zonas de desarrollo reales y potenciales de los discentes. Se anhela que en una educación inclusiva haya rupturas de paradigmas en el ambiente escolar. De esta forma nuevas prácticas pedagógicas deben ser construidas, posibilitando el desarrollo de las capacidades y potencialidades de los alumnos, buscando su desarrollo integral y proporcionando el intercambio de informaciones y conocimientos por todos los involucrados en los procesos de enseñanza y aprendizaje. Vislumbrando contemplar ese escenario, también se hace un análisis reflexivo sobre el ordenamiento legal que hace referencia a la Educación Especial en una perspectiva inclusiva en la EJA.

Palabras clave: Trabajo colaborativo- Inclusión- EJA- Matemática

\footnotetext{
${ }^{1}$ Mestranda em Educação Profissional: Universidade Federal do Pampa - UNIPAMPA; Jaguarão; Rio Grande do Sul; Brasil; katiusciadiasortiz@gmail.com
} 


\begin{abstract}
This article deals with the limits and possibilities of collaborative work among students as a strategy in the learning of Mathematics, in the inclusion of students with intellectual disabilities, in Youth and Adult Education (EJA) and based on the Historical-Cultural Theory of Activity (CHAT). Stetsenko (2016) emphasizes that the learner must go through teaching and learning experiences, that they make available the necessary tools to solve problems in collaboration with others, allowing the student to have an active voice within the school context, enhancing the knowledge to be constituted collective form. In this context, it is up to the teacher to mediate and observe the teaching and learning processes of the students of the EJA, enabling pedagogical strategies that stimulate the real and potential development zones of the students. It is hoped that in an inclusive education there will be ruptures of paradigms in the school environment. In this way new pedagogical practices must be built, allowing the development of the capacities and potential of the students, seeking their integral development and providing the sharing of information and knowledge by all involved in the teaching and learning processes. Looking to contemplate this scenario, there is also a reflexive analysis on the legal order that refers to Special Education in an inclusive perspective in the EJA.
\end{abstract}

Keywords: Collaborative work- Inclusion- EJA- Mathematics

\title{
1.Introdução
}

Almeja-se que numa educação inclusiva haja rupturas de paradigmas no ambiente escolar, possibilitando o desenvolvimento das capacidades e potencialidades dos alunos. Desta forma novas práticas pedagógicas devem ser construídas, buscando o desenvolvimento integral do educando e proporcionando o compartilhamento de informações e conhecimentos por todos os envolvidos nos processos de ensino e aprendizagem. Para melhor entender esse cenário faz-se uma análise reflexiva sobre o ordenamento legal referente a Educação Especial numa perspectiva inclusiva na EJA. A Lei de Diretrizes e Bases da Educação (LDB), $\mathrm{n}^{\circ}$ 9.394/96, em seu artigo 37 estabelece que:

A educação de jovens e adultos será destinada àqueles que não tiveram acesso ou continuidade de estudos no ensino fundamental e médio na idade própria.

Parágrafo $1^{\circ}$ - os sistemas de ensino assegurarão gratuitamente aos jovens e adultos, que não puderam efetuar os estudos na idade regular, oportunidades educacionais apropriadas, consideradas as características do alunado, seus interesses, condições de vida e de trabalho, mediante cursos e exames. (BRASIL, 1996, p. 15)

As Diretrizes da Política Nacional de Educação Especial na Perspectiva Inclusiva (PNEEPEI) salienta que nessa modalidade de ensino "as ações da educação especial possibilitam a ampliação de oportunidades de escolarização, formação para a inserção no mundo do trabalho e efetiva participação social” (BRASIL, 2008, p. 17).

Conforme a Constituição Federal de 1988 em seu artigo 205, "a educação, direito de todos e dever do Estado e da família, será promovida e incentivada com a colaboração da sociedade, visando ao pleno desenvolvimento da pessoa, seu preparo para o exercício da cidadania e sua qualificação para o trabalho" (CF, p. 121). E tem como objetivo fundamental 
em seu artigo $3^{\circ}$, inciso IV "promover o bem de todos, sem preconceitos de origem, raça, sexo, cor, idade e quaisquer outras formas de discriminação". Destaca ainda em seu artigo $5^{\circ}$ que: "[t]odos são iguais perante a lei, sem distinção de qualquer natureza [...]."

As Diretrizes Nacionais para a Educação Especial na Educação Básica, Resolução $\mathrm{CNE} / \mathrm{CEB} \mathrm{n}^{\circ} 2 / 2001$, em seu artigo $2^{\circ}$ determina que:

Os sistemas de ensino devem matricular todos os alunos, cabendo às escolas organizarem-se para o atendimento aos educandos com necessidades educacionais especiais, assegurando as condições necessárias para uma educação de qualidade para todos (BRASIL, 2001, p. 69).

Uma escola inclusiva deve, então, levar em conta a diversidade de cada pessoa, respeitando as diferenças, sejam elas de: raça, credo, aprendizagem ou níveis sociais. E o professor deve ser um mediador que estimula e incentiva seus alunos nos processos de ensino e de aprendizagem.

Para a concretização desta educação é importante que haja a atuação de todos os envolvidos no processo educativo e o comprometimento de toda equipe escolar, bem como a participação da família, pois este papel não é de responsabilidade somente do professor. Segundo as Diretrizes da Política Nacional de Educação Especial na perspectiva inclusiva:

[...] a educação especial passa a integrar a proposta pedagógica da escola regular, promovendo o atendimento às necessidades educacionais especiais de alunos com deficiência, transtornos globais de desenvolvimento e altas habilidades/superdotação. Nestes casos e outros, que implicam em transtornos funcionais específicos, a educação especial atua de forma articulada com o ensino comum, orientando para o atendimento às necessidades educacionais especiais desses alunos (BRASIL, 2007, p. 15).

Segundo a LDB, em seu artigo 12 (p. 6), “os estabelecimentos de ensino, respeitadas as normas comuns e as do seu sistema de ensino, terão a incumbência de elaborar e executar sua proposta pedagógica" e em seu artigo 14 destaca que:

[...] os sistemas de ensino definirão as normas da gestão democrática do ensino público na educação básica, de acordo com as suas peculiaridades e conforme os seguintes princípios: I- participação dos profissionais da educação na elaboração do projeto pedagógico da escola; II- participação das comunidades escolares e local em conselhos escolares ou equivalentes (BRASIL, 1996, p. 7).

Conforme as Diretrizes Curriculares Nacionais para a Educação de Jovens e Adultos em seu artigo 17: 
A formação inicial e continuada de profissionais para a Educação de Jovens e Adultos terá como referência as diretrizes curriculares nacionais para o ensino fundamental e para o ensino médio e as diretrizes curriculares nacionais para a formação de professores, apoiada em:

I - ambiente institucional com organização adequada à proposta pedagógica;

II - investigação dos problemas desta modalidade de educação, buscando oferecer soluções teoricamente fundamentadas e socialmente contextuadas;

III - desenvolvimento de práticas educativas que correlacionem teoria e prática;

IV - utilização de métodos e técnicas que contemplem códigos e linguagens apropriados às situações específicas de aprendizagem (BRASIL, 2000, p. 3).

Desta forma, então, as escolas devem reorganizar seu Projeto Político Pedagógico (PPP), enfatizando e proporcionando a construção de novas práticas pedagógicas que favoreçam o ensino de qualidade para todos, sem discriminação, reconhecendo as diferenças e as individualidades promovendo a participação de todos os educandos indistintamente. Segundo Ropoli et al:

O Projeto Político Pedagógico é o instrumento por excelência para melhor desenvolver o plano de trabalho eleito e definido por um coletivo escolar; ele reflete a singularidade do grupo que o produziu, suas escolhas e especificidades (2010, p. 10).

Desta forma, evidencia-se que em busca de uma educação inclusiva essas mudanças, devem estar explicitadas no PPP, e necessitam ser elaboradas a partir de uma gestão escolar democrática, que possibilite a participação de todos: professores, gestores, especialistas, pais e profissionais envolvidos com a educação.

Segundo Notas Estatísticas do Censo Escolar do Instituto Nacional de Estudos e Pesquisas Educacionais Anísio Teixeira (INEP, 2016, p. 4) “57,8\% das escolas brasileiras têm alunos com deficiência, transtornos globais do desenvolvimento ou altas habilidades incluídos em classes comuns. Em 2008, esse percentual era de apenas 31\%”, o que nos mostra um aumento significativo. Nessa perspectiva a escola inclusiva deve ser um espaço de formação integral, trabalhando com a diversidade, valorizando a capacidade de cada um, desenvolvendo as potencialidades e habilidades, proporcionando meios para a formação de um cidadão consciente, crítico, capaz de interpretar e compreender o mundo em que está inserido.

Neste contexto, cabe ao professor mediar e observar os processos de ensino e aprendizagem dos alunos da EJA, possibilitando estratégias pedagógicas que estimulem as zonas de desenvolvimento reais e potenciais dos discentes. Desta forma, salienta-se que o processo de avaliação deve ser contínuo e não classificatório, percebendo assim, o que o aluno sabe, o que precisa aprender, como pode aprender, o que precisa ser modificado para que a aprendizagem seja oportunizada, construindo uma reflexão contínua sobre os aspectos de desenvolvimento real de sua aprendizagem. 
Arroyo (2001, p. 11) diz que "[a] educação popular e a EJA enfatizaram uma visão totalizante do jovem e do adulto como ser humano, com direito a se formar ser pleno, social, cultural, cognitivo, ético, estético, de memória". Reitera-se, então, que a escola deve ser um ambiente estimulante e o professor deve ser um mediador que promova autonomia e que possibilite o educando novas descobertas do seu potencial, estruturando seus planejamentos de forma dinâmica, inovadora e criativa, incentivando as potencialidades e as habilidades desenvolvendo assim as aptidões deste aluno. Conforme Gomes, Poulin e Figueiredo:

É importante considerar que a interação do aluno com seus pares na classe comum fazem dele um agente participativo que contribui ativamente para a constituição de um saber compartilhado. O aluno deverá perceber-se como sujeito que contribui para a construção de saberes coletivos, retirando disso múltiplas vantagens, inclusive a de acessar um papel social valorizado. Oportunizar ao aluno com deficiência intelectual viver integralmente a sua escolarização no espaço da sala de aula comum permite que ele se beneficie dessa convivência (2010, p. 18).

A pessoa com deficiência apresenta uma série de particularidades que interferem no desenvolvimento "normal", na comunicação coletiva, na colaboração e na interação com outros sujeitos de seu convívio. Separá-los desta coletividade faz com que demonstrem dificuldade no seu desenvolvimento social, determinando assim o desenvolvimento incompleto das funções psíquicas superiores tornando-as precárias. As funções psíquicas superiores envolvem as capacidades psicológicas, elas são fruto do desenvolvimento histórico da humanidade e originam as dificuldades secundárias. Já as funções psicológicas elementares são aquelas das quais os seres vivos já nascem, chamadas de reações biológicas, e estão relacionadas as dificuldades primárias.

Neste sentido, cabe ao educador a importante função de procurar estratégias que envolvam o educando, de tal forma que este possa estar motivado a realizar as atividades que lhe são propostas, possibilitando que seu processo de ensino e aprendizagem seja dinâmico e criativo.

Vygotski destaca que a construção do conhecimento envolve uma ação que deve abranger a todos, requerendo uma cooperação e troca de informações mútuas, que consequentemente ampliará as competências individuais. Percebe-se então, que o envolvimento dos discentes de maneira conjunta pode possibilitar benefícios que não estariam acessíveis na aprendizagem individualizada. Colomina e Onrubia ressaltam que:

A aprendizagem escolar é concebida como um processo construtivo que tem um caráter intrinsecamente social, interpessoal e comunicativo, e o ensino, como um processo complexo de estruturação e guia, mediante apoios e suportes diversos, 
dessa construção; portanto, um processo no qual os outros alunos têm um papel natural com fontes potenciais de ajuda educacional (2004, p. 280).

O docente deve proporcionar, então, momentos de troca e interação entre os discentes, estimulando a participação ativa destes indivíduos, promovendo ações em grupos que sucedam a elaboração das próprias habilidades de aprendizagem e viabilizando a transformação do ensino onde seu conhecimento prévio e a interação entre eles é fator essencial para sua aprendizagem. Para Coll e Colomina o trabalho colaborativo possibilita a:

confrontação entre pontos de vista moderadamente divergentes como fator determinante do progresso intelectual. A existência de enfoques diferentes em torno de uma mesma situação ou tarefa traduz-se, em função da exigência de uma atividade grupal comum, em um conflito sócio-cognitivo, que mobiliza e força as restruturações cognitivas e provoca, desta maneira, o progresso intelectual. (1996, p. 308)

Para Vygotski, tanto a constituição dos sujeitos como os processos de pensamento e seu aprendizado decorrem pela relação com outras pessoas. Neste sentido o trabalho colaborativo entre os discentes é o cerne deste artigo, pois propicia situações cooperativas e estas podem possibilitar a construção de conhecimentos em conjunto com seu grupo. Vygotski ressalta que na CHAT o indivíduo aprende e se desenvolve em interação com o outro e destaca que:

[...] um aspecto essencial do aprendizado é o fato de ele criar a zona de desenvolvimento proximal; ou seja, o aprendizado desperta vários processos internos de desenvolvimento, que são capazes de operar somente quando se interage com pessoas em seu ambiente e quando em cooperação com seus companheiros. Uma vez internalizados, esses processos tornam-se parte das aquisições do desenvolvimento (1998, p. 101).

Desta forma, os alunos através da convivência com outros sujeitos podem construir conhecimentos ao longo das situações colaborativas que foram propostas. Nesta perspectiva, a teoria da atividade preconiza o aprendizado por intermédio das interações com o meio sociocultural, propiciando o desenvolvimento dos educandos e da própria atividade. Para Onrubia, Rochera e Barberà:

... os alunos não aprendem recebendo e acumulando passivamente informação do ambiente, mas que o fazem por meio de um processo ativo de elaboração de significados e de atribuição de sentidos; um processo que se realiza mediante a interação, a negociação e a comunicação com outras pessoas em contextos particulares culturalmente definidos e no qual determinados artefatos, e instrumentos culturais também desempenham um papel decisivo. No caso particular da Matemática, isso significa que o conjunto de elementos cognitivos e afetivos a que acabamos de nos referir como envolvidos no uso especializado da matemática é 
adquirido mediante esse processo de construção social e culturalmente mediada (2004, 332).

Sendo assim, as atividades desenvolvidas sob a óptica da CHAT tencionam modificar os objetivos em resultados, através da ação, proporcionando a metamorfose do trabalho que contemplem as necessidades dos discentes na comunidade. Segundo Onrubia, Rochera e Barberà é fundamental:

Ancorar a aprendizagem da matemática na sala de aula em situações concretas e significativas para os alunos é essencial para que as vantagens oferecidas pela descontextualização cognitiva própria do conhecimento matemático não sejam anuladas pela descontextualização social e afetiva (2004, p. 334).

Essa conjuntura de atividades pode possibilitar aos discentes desenvolver além da interação e comunicação, contextos cognitivos e construtivistas sobre a aprendizagem, entre os estudantes no âmbito da sala de aula. Segundo Cubero e Luque (2004, p.105) "[a] teoria sociocultural entende a aprendizagem como um processo distribuído, interativo, contextual e que é resultado da participação dos alunos em uma comunidade de prática".

Colomina e Onrubia (2004, p. 289) ressaltam que cabe ao professor "manejar, de modo efetivo, a heterogeneidade do grupo classe a serviço do rendimento acadêmico dos alunos", de forma que a intervenção possibilite a equidade do convívio e do conhecimento para todos os envolvidos, oportunizando as interações construtivas. Conforme Cubero e Luque:

A apropriação de objetos de conhecimentos e de ferramentas culturais mediada pela ajuda de outros supõe:

a) Incorporar o objeto de conhecimento ou a nova ferramenta cultural aos recursos mentais disponíveis até esse momento por parte do aluno;

b) Fazer seu o conhecimento e a ferramenta cultural aprendidos, dando-lhes um sentido e um significado;

c) Incluí-los no repertório de práticas utilizada;

d) Compartilhar seu uso com os demais. (2004, p. 105)

Evidencia-se que a aprendizagem é um processo que ocorre durante toda a vida, desde o nascimento até a morte, e durante todo esse encadeamento o ser humano deve estimular suas habilidades que lhe proporcionam autonomia para desenvolver-se como ser social. Segundo Onrubia, Rochera e Barberà (2004) a educação matemática deve:

1- Contextualizar a aprendizagem da matemática em atividades autênticas e significativas para os alunos (p. 334).

2- Orientar a aprendizagem dos alunos para compreensão e a resolução de problemas (p. 334).

3- Vincular a linguagem formal matemática com seu significado referencial ( $\mathrm{p}$. 
4- Ativar e empregar como ponto de partida o conhecimento matemático prévio, formal e informal, dos alunos (p. 336).

5- Avançar de maneira progressiva a níveis cada vez mais elevados de abstração e de generalização (p. 336).

6- Ensinar explicitamente, e de maneira informada, estratégias e habilidades matemáticas de alto nível (p. 337).

7- Sequenciar adequadamente os conteúdos matemáticos, assegurando a interrelação entre as distintas capacidades envolvidas na aquisição do conhecimento matemático (p. 337).

8- Apoiar sistematicamente o ensino na interação e na cooperação entre alunos (p. 338).

9- Oferecer aos alunos oportunidades suficientes para "falar matemática" na sala de aula (p. 338).

10- Dar atenção aos aspectos afetivos e motivacionais envolvidos na aprendizagem e no domínio da matemática (p. 339).

Coll e Colomina (1996, p. 299) destacam que os "alunos podem exercer, em determinadas circunstâncias, uma influência educativa sobre seus colegas; ou, em outras palavras, de que podem desempenhar o papel mediador..." auxiliando-os e otimizando a resolução de situações problema.

É primordial, então, que os alunos sejam incentivados a trabalhar com os diferentes tipos de atividades nos processos de ensino e aprendizagem, pois através delas é que estaremos proporcionando momentos de interação e busca da construção do conhecimento proporcionando assim o desenvolvimento intelectual e social.

Coll e Colomina (1996) ressaltam que a organização social das atividades de aprendizagem na aula, podem ser estruturadas em três formas: cooperativa, competitiva e individualista. É na visão cooperativa que se constitui o trabalho colaborativo, pois "[e]m uma organização cooperativa das atividades de aprendizagem, os resultados que cada membro do grupo busca são igualmente benéficos para os restantes membros, com os quais está interagindo cooperativamente", estes trabalham juntos durante a execução do desenvolvimento e resolução das atividades.

Um dos grandes desafios encontrados nas escolas, referentes ao ensino e aprendizagem das crianças e adolescentes tem sido as dificuldades de aprendizagem que os alunos apresentam. Segundo Vygotski (1997) a coletividade é fundamental para o desenvolvimento pessoal e social, pois proporciona aguçar novas possibilidades, proporcionando desenvolver as aptidões, a colaboração, a interação e as habilidades do sujeito. Sendo assim, o professor deve se organizar de forma a desenvolver um trabalho coletivo, interdisciplinar e colaborativo, pois esta articulação possibilitará a evolução do aluno, em seus aspectos cognitivos, afetivos e sociais, incluindo o educando nas atividades propostas na sala de aula 
juntamente com os demais alunos, desafiando a realizá-las, superando suas dificuldades e estimulando sua inteligência.

Segundo Abramowicz (1997) é imprescindível que a escola reconheça que os educandos da EJA são agentes de aprendizagem, com potencialidades para aprender e ampliar habilidades e capacidades, desenvolvendo sua inteligência nas diferentes áreas do conhecimento, mediadas pela interação com outros sujeitos. Evidencia-se que todos temos direito de aprender, pois a aprendizagem é uma condição humana e está presente durante nossa existência, destaca-se que somos seres heterogêneos e em constante evolução. Neste contexto, é importante que os docentes proporcionem o trabalho colaborativo entre os discentes, visto que este tipo de atividade é uma estratégia de ensino que os envolve na coletividade, proporcionando a superação de suas limitações e a inclusão de todos nos processos de ensino e aprendizagem.

\section{Referências}

ABRAMOWICZ, J. (org.) Para Além do Fracasso Escolar. Campinas, SP: Papirus, 1997.

ARROYO, M. A Educação de Jovens e Adultos em Tempos de Exclusão. Alfabetização e Cidadania: Revista de Educação de Jovens e Adultos. São Paulo: n. 11, p. 9-20, abr. 2001.

BRASIL. Constituição da República Federativa do Brasil. Brasília: Impressa Oficial, 1988.

Ministério da Educação. Diretrizes Curriculares Nacionais para a Educação e Jovens e Adultos. Resolução CNE/CEB No 1, de 5 de julho de 2000.

Ministério da Educação. Diretrizes Nacionais para a Educação Especial na Educação Básica. Resolução CNE/CEB No 2, de 11 de setembro de 2001.

. Ministério da Educação. Instituto Nacional de Estudos e Pesquisas Educacionais Anísio Teixeira. Sinopse Estatística da Educação Básica. 2017. Brasília: Inep, 2018. Disponível em: 〈http://portal.inep.gov.br/sinopses-estatisticas-da-educacao-basica〉. Acesso em: 10 nov. 2018.

Ministério da Educação. Lei de Diretrizes e Bases da Educação Nacional. LDB n ${ }^{\circ}$ 9394, de 20 de dezembro de 1996.

Ministério da Educação. Secretaria de Educação Especial. Política Nacional de Educação Especial na Perspectiva da Educação Inclusiva. Brasília: MEC/SEESP, 2008.

Ministério da Educação. Secretaria de Educação Especial. Política Nacional de Educação Especial na Perspectiva da Educação Inclusiva. Brasília: MEC/SEESP, 2007. Disponível em: $<$ http://portal.mec.gov.br/index.php?option=com_docman\&view=download\&alias=16690- 
politica-nacional-de-educacao-especial-na-perspectiva-da-educacao-inclusiva05122014\&Itemid=30192 > . Acesso em: 20 nov. 2018.

COLL, C; COLOMINA, R. Interação entre alunos e aprendizagem escolar. In: COLL, C. (Org). Desenvolvimento psicológico e educação: psicologia da educação. Porto Alegre: Artes Médicas Sul, v. 2, 1996. p. 298-314.

COLOMINA, R; ONRUBIA, J. Interação educacional e aprendizagem escolar: a interação entre alunos. In: COLL, C. (Org). Desenvolvimento psicológico e educação. $2^{\mathrm{a}}$ ed. Porto Alegre: Artmed, v. 3, 2004. p. 280-293.

CUBERO, R; LUQUE, A. Desenvolvimento, educação e educação escolar: a teoria sociocultural do desenvolvimento e da aprendizagem. In: COLL, C. (Org). Desenvolvimento psicológico e educação. 2a ed. Porto Alegre: Artmed, v. 3, 2004. p. 94-106.

GOMES, A; POULIN, J; FIGUEIREDO, R. A Educação Especial na Perspectiva da Inclusão Escolar: o atendimento educacional especializado para os alunos com deficiência intelectual. Brasília: Ministério da Educação, Secretaria da Educação Especial. Universidade do Ceará, 2010.

ONRUBIA, J; ROCHERA, M. J; BARBERÀ, E. O ensino e a aprendizagem da matemática: uma perspectiva psicológica. Desenvolvimento psicológico e educação. $2^{\mathrm{a}}$ ed. Porto Alegre: Artmed, 2004. p. 327-341.

STETSENKO, A. Vygotsky's theory of method and philosophy of practice: implications for trans/formative methodology. Revista Educação. Porto Alegre, v. 39, n. esp. (supl.), s32-s41, dez. 2016.2 Disponível em: <http://revistaseletronicas.pucrs.br/ojs/index.php/faced/article/view/24385>. Acesso em: 23 nov. 2018.

VYGOTSKI, L. S. A formação social da mente. $6^{a}$ ed. São Paulo: Martins Fontes, 1998.

VYGOTSKI, L. S. Obras escogidas. Volume V. Fundamentos de defectología. Tradução: Julio Guillermo Blank. Madrid: Visor, 1997. 